\title{
Analysis On Phase Shift Method Of Stealing Electricity Meter Wiring
}

\author{
Feng Bo $\mathrm{Gu}^{1}$, a \\ ${ }^{1}$ State Grid Cangzhou Electric Power Supply Company,No.18.Xinhua East Road,Xinhua \\ District,Cangzhou City,Hebei Prov,China,061000 \\ aczgufengbo@163.com
}

Keywords: Power factor angle; Electric larceny; Anti electric larceny; Power supply; Phase diagram

\begin{abstract}
The electric energy meter error for system operation because of stealing brings, will cause loss of energy meter measuring electric energy electricity, and affect accuracy and integrity of energy settlement. In real work, we not only need to view real-time electric energy meter display and measurement value which copied back by remote meter reading system, for example the secondary current, voltage, power, power factor, use instrument and phasor diagram in order to analyze and judge the electric energy meter running state whether there is electricity stealing to the user of electricity consumption of the large fluctuation. Calculating the corresponding correct electricity and electricity stealing amount can provide technology guarantee for the accurate measurement of electric energy.
\end{abstract}

\section{Introduction}

To ensure the accuracy and fairness of electric power measurement is always the goal of electric power enterprises. At the same time, the accuracy of power measurement can provide basic guarantee for mutual benefit. With the rapid development of science and technology, the traditional electric energy meter which is destructive is less and less especially in the high voltage of stealing electricity, the way is also more and more advanced(see [1-10]).

One of the most common, is also the most difficult method is starting from the basic principle of power measurement to change the meter secondary loop wiring and circuit structure in order to make the meter more slowly and steal electricity.

It isn't too hard to see the methods of stealing electricity are under- voltage, shunt, phase -shift, destruction.Below I will analysis the method of phase shifting method.

\section{The principle of three-phase three wire electric energy metering device}

For three-phase three wire electric energy meter, the phasor diagram as shown in Figure 1.

In Figure 1, $\Phi \mathrm{a} 、 \Phi \mathrm{b} 、 \Phi \mathrm{c}$ are power factor angle, $\mathrm{Ua} 、 \mathrm{Ub} 、 \mathrm{Uc}$ are the secondary phase voltage , Ia Ic are the secondary phase current.

The right wiring of the three-phase three wire electric energy meter is: the element 1 uses line voltage Uab and phase current Ia, the element 2 uses line voltage Ucb and phase current Ic, expression of instantaneous power is $\mathrm{P}=\mathrm{UabIa}+\mathrm{UcbIc}=\sqrt{3} \mathrm{UI} \cos \Phi$ 。 The practical work, we can preliminary analysis of the user's meter connection is normal by comparing instantaneous power which calculated from real-time voltage, current with power meter display. 


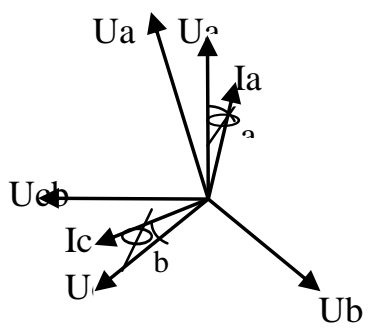

Figure. 1 The phasor diagram of three-phase three wire electric energy meter

From the above, the amount of power of electric energy meter measuring mainly depends on the product of three elements of voltage, current, power factor and time.

On site inspection, we can adopt the following simple method in order to distinguish electric energy meter wiring is correct:

First of all, for any electric energy meter of positive rotation, if the original electric energy meter wiring is correct, through exchange any two voltage into the line three times, the electric energy meter should be stopped three times, Otherwise, wiring must be a mistake. Its power is calculated as follow for meter of right wiring after exchange any two voltage into the line:

Exchange A、B phase voltage, its power as follow:

$$
\begin{aligned}
& \mathrm{P} 1=U_{\mathrm{ba}} I_{\mathrm{a}} \cos \left(150^{\circ}-\Phi_{\mathrm{a}}\right)=-U I \cos \left(30^{\circ}+\Phi\right) \\
& \mathrm{P} 2=U_{\mathrm{ca}} I_{\mathrm{c}} \cos \left(30^{\circ}+\Phi_{\mathrm{c}}\right)=U I \cos \left(30^{\circ}+\Phi\right) \\
& \mathrm{P}=\mathrm{P} 1+\mathrm{P} 2=0
\end{aligned}
$$

Exchange B、C phase voltage, its power as follow:

$$
\begin{aligned}
& \mathrm{P} 1=U_{\mathrm{ac}} I_{\mathrm{a}} \cos \left(30^{\circ}-\Phi_{\mathrm{a}}\right)=U I \cos \left(30^{\circ}-\Phi\right) \\
& \mathrm{P} 2=U_{\mathrm{bc}} I_{\mathrm{c}} \cos \left(150^{\circ}+\Phi_{\mathrm{c}}\right)=-U I \cos \left(30^{\circ}-\Phi\right) \\
& \mathrm{P}=\mathrm{P} 1+\mathrm{P} 2=0 \\
& \text { Exchange } \mathrm{A} 、 \mathrm{C} \text { phase voltage, its power as follow: }
\end{aligned}
$$

$$
\begin{aligned}
& \mathrm{P} 1=U_{\mathrm{cb}} I_{\mathrm{a}} \cos \left(90^{\circ}+\Phi_{\mathrm{a}}\right)=-U I \cos \left(90^{\circ}-\Phi\right) \\
& \mathrm{P} 2=U_{\mathrm{ab}} I_{\mathrm{c}} \cos \left(90^{\circ}-\Phi_{\mathrm{c}}\right)=U I \cos \left(90^{\circ}-\Phi\right) \\
& \mathrm{P}=\mathrm{P} 1+\mathrm{P} 2=0
\end{aligned}
$$

The power of the electric energy meter calculation shows that if the original wiring is correct after exchange any two voltage into the line three times, the meter should be stopped (or micro).

It just shows the meter could be right which the meter stopped after exchange any two voltage into the line three times. It is a necessary condition for the right wiring, but not a sufficient one which meter stop after exchange two voltage, So we must do further study. It follow as: First of all, revolutions per minute of meter are reduced to half of the original(Multifunctional electric energy meter power is half of the original) after disconnect B phase voltage .Its power as follow:

$$
\begin{aligned}
& \mathrm{P} 1=1 / 2 \mathrm{UacIacos}\left(30^{\circ}-\Phi \mathrm{a}\right)=\mathrm{UI} \cos \left(30^{\circ}-\Phi\right) \\
& \mathrm{P} 2=1 / 2 \mathrm{U} \operatorname{caIccos}\left(30^{\circ}+\Phi \mathrm{c}\right)=\mathrm{UI} \cos \left(30^{\circ}+\Phi\right)
\end{aligned}
$$




$$
\mathrm{P}=\mathrm{P} 1+\mathrm{P} 2=\mathrm{UI} \cos \Phi
$$

From the power calculation of the power shows that the rotational speed (magnitude of power)after disconnect B phase voltage should be reduced by half when the meter wiring is right, and then it will be make meter stop by exchanging the $\mathrm{A}, \mathrm{C}$ phase voltage into the line, Continue, disconnect the A phase voltage, its power follow as:

$$
\mathrm{P} 1=\mathrm{U} \operatorname{cbIacos}\left(90^{\circ}+\Phi \mathrm{a}\right)=\mathrm{UI} \cos \left(90^{\circ}+\Phi\right)=-\mathrm{UI} \sin \Phi
$$

Disconnect the $\mathrm{C}$ phase voltage, its power follow as:

$$
\mathrm{P} 2=\mathrm{UabIccos}\left(90^{\circ}-\Phi \mathrm{c}\right)=-\mathrm{UI} \cos \left(90^{\circ}-\Phi\right)=\mathrm{UI} \sin \Phi
$$

Power P1 and P2 equal in size, in the opposite direction. It shows that meter revolutions are same, but in the opposite direction after disconnect twice for any user power factor.

It can jugde the meter wiring is right which by observing the state of electric energy meter after exchange any two voltage into the line and disconnect phase voltage separately. The comprehensive analysis and calculation of the electric energy meter wiring error many of results shows that, for any of the wrong wiring case, combinations that are unlikely to occur simultaneously in these six cases. If the case is different from the above cases, that wrong wiring or stealing is considered.

So we know, we can change meter secondary voltage, current phase by using phase shift method of stealing electricity in order to make the meter walk faster, more slowly and stop. Of course, thieves cannot make the electric energy meter walk faster. There are many conditions of meter walk more slowly and stop. Now we analyze two of many conditions.

\section{Analysis on phase shift method of stealing electricity}

Firstly, we analyze the electric energy meter stop conditions:

The three-phase three wire electric energy meter, the element 1 uses line voltage Ucb and phase current Ia, the element 2 uses line voltage Uab and phase current Ic 。The phasor diagram as shown in Figure 2.

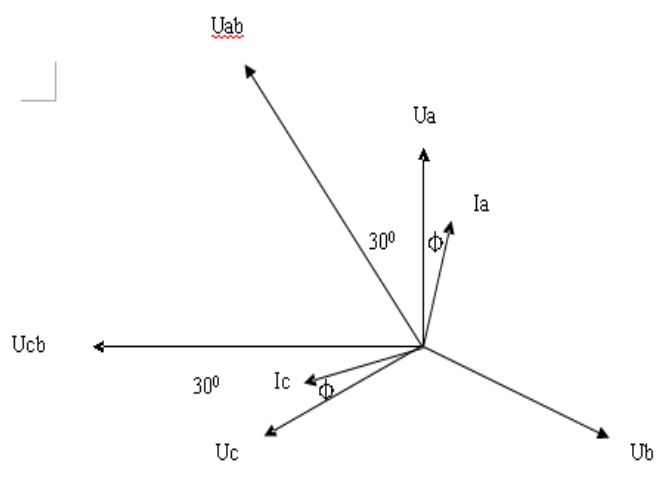

Figure. 2 The phasor diagram of three-phase three wire electric energy meter 2

In Figure 2, $\Phi \mathrm{a} 、 \Phi b 、 \Phi c$ are power factor angle, $\mathrm{Ua} 、 \mathrm{Ub} 、 \mathrm{Uc}$ are the secondary phase voltage , Ia、 Ic are the secondary phase current.

Expression of instantaneous power is:

$$
\mathrm{P} 1=\mathrm{Ucb} * \mathrm{Ia}^{*} \cos (900+\Phi)
$$




$$
\begin{aligned}
& \mathrm{P} 2=U_{\mathrm{ab}} * I_{\mathrm{c}} * \cos \left(90^{0}-\Phi\right) \\
& \mathrm{P}=\mathrm{P} 1+\mathrm{P} 2=0
\end{aligned}
$$

So, We came to an conclusion that how much the user electricity load, the electric energy meter basic no measurement when use the phase shift method of stealing electricity. Because this method can make that the electric energy meter is basically not go, but the actual power load is real time , So this method is very easy to be found. With the condition of line loss management is becoming more and more stringent, user basically don't use this method of electric stealing.

Secondly, we analyze the electric energy meter walk more slowly conditions:

The three-phase three wire electric energy meter, the element 1 uses line voltage Uba and phase current -Ia, the element 2 uses line voltage Uca and phase current Ic 。The phasor diagram as shown in Figure 3.

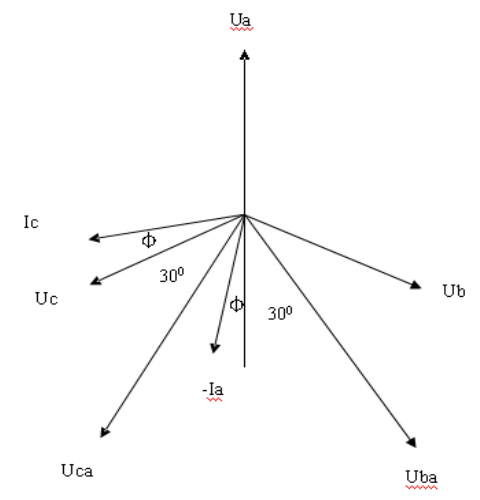

Figure. 3 The phasor diagram of three-phase three wire electric energy meter 3

In Figure 3, $\Phi \mathrm{a} 、 \Phi \mathrm{b} 、 \Phi \mathrm{c}$ are power factor angle, $\mathrm{Ua} 、 \mathrm{Ub} 、 \mathrm{Uc}$ are the secondary phase voltage , Ia Ic are the secondary phase current.

Expression of instantaneous power is:

$$
\begin{aligned}
& \mathrm{P} 1=\mathrm{Uba}^{*}(-\mathrm{Ia}) * \cos (300+\Phi) \\
& \mathrm{P} 2=\mathrm{Uca} * \mathrm{Ic} * \cos (300+\Phi) \\
& \mathrm{P}=\mathrm{P} 1+\mathrm{P} 2=2 \mathrm{UI} \cos (300+\Phi)
\end{aligned}
$$

So, Expression of instantaneous power is $\mathrm{P}=\sqrt{3} \mathrm{UI}$ when the power factor angle is $0^{\circ}$

Expression of instantaneous power is $\mathrm{P}=\mathrm{UI}$ when the power factor angle is $30^{\circ}$

Expression of instantaneous power is $\mathrm{P}=0$ when the power factor angle is $60^{\circ}$

So we know that, when the power factor angle becomes larger, the three-phase three wire electric energy meter measuring instantaneous power becomes smaller, when the power factor angle closer to 600 , the meter close to no measurement.

From the expression on the correct wiring of power section $(P=\sqrt{3} U$ I $\cos \Phi)$ can be seen, when the power factor angle is 00 , instantaneous power expression is $\mathrm{P}=\sqrt{3} \mathrm{UI}$.

Therefore, we conclude that, in the event of phase shift method of stealing electricity, when the power factor is close to 1 , i.e., the power factor angle is close to 00 , the electric energy meter is basic normal measurement. When the power factor is close to 0.5 , i.e., the power factor angle is close to 600 , the electric energy meter basic no measurement.

When we go to check one user, we will find that the power factor is close to 1 also the voltage, current, secondary power are normal, but the power factor is maintained at about 0.7 from the remote meter reading system. It is not difficult to explain why the user is always make the reactive 
power compensation device is put into operation before our staff to check, and has not been put into operation after our check.

\section{Summary}

So we can see from the above analysis that, it is very subtle when the user adopts the phase shift method of stealing electricity. When the power factor is close to 1 , it is very difficult to find the stealing electricity behavior of user that by comparing instantaneous power which calculated from real-time voltage, current with power meter display. Therefore, From beginning to end when we check user we must observe the fluctuation power consumption of user every month and the usage of the reactive power compensation device, we also must use the phase volt ampere meter and the on-site checking instrument to measure voltage, current, secondary power, phase on spot. When necessary we can also move the measurement point up and use of high voltage metering box outdoor, so as to ensure the electric energy metering accuracy and fairness.

\section{References}

[1] B. Kamala Latha,Regina Jose,K. P. N. Murthy et al.Detection of an intermediate biaxial phase in the phase diagram of biaxial liquid crystals: Entropic sampling study[J].Physical review, E. Statistical, nonlinear, and soft matter physics,2014,89(5 Pt.A):050501-1-050501-5.

[2] Jendrik Stein,Ralf Erich Schacherl,Minsu Jung et al.Solubility of nitrogen in ferrite; the Fe-N phase diagram[J].International Journal of Materials Research,2013,104(11):1053-1065.

[3] A. Sheikhi,Sh. Bahrami,A.M. Ranjbar et al.Strategic charging method for plugged in hybrid electric vehicles in smart grids; a game theoretic approach[J].International journal of electrical power and energy systems,2013,53(Dec.):499-506.

[4] Sarojini, K.G.K.,Manoj, S.V.,Singh, P.K. et al.Electrical conductivity of ceramic and metallic nanofluids[J].Colloids and Surfaces, A. Physicochemical and Engineering Aspects, 2013,417:39-46.

[5] L. G. Kaake,A. Jailaubekov,K. J. Williams et al.Probing ultrafast charge separation at organic donor/acceptor interfaces by a femtosecond electric field meter[J].Applied physics letters,2011,99(8):083307-1-083307-3.

[6] Sanqiang Wang,Xingzhe Hou,Yanlin Liu et al.Electronic type electric energy meter calibrating method application research[C].//Advances in mechatronics and control engineering.2013:983-986.

[7] Xin Liu,Zhanjun Wu,Rongguo Wang et al.Experimental Study of the Electrical Resistivity of Glass-carbon/ Epoxy Hybrid Composites[J].Polymers \&amp; Polymer Composites,2014,22(3):289-292.

[8] Yishun Liao,Xiaosheng Wei.Relationship between Chemical Shrinkage and Electrical Resistivity for Cement Pastes at Early Age[J].Journal of Materials in Civil Engineering,2014,26(2):384-387.

[9] D.Gallo, A.Liccardo, N.Pasquino, "Performance Analysis Of An Active Energy Induction Meter Using An Innovative Approach" XVIII IMEKO World Congress Sept., 17 - 22, 2006, Brazil;

[10] Crespi, L.,Ghetti, A.,Boniardi, M. et al.Electrical Conductivity Discontinuity at Melt in Phase Change Memory[J].IEEE Electron Device Letters,2014,35(7):747-749. 